\title{
Involving communities in health service planning in primary care
}

\author{
Sue Kirk MSc BNurs RN RM RHV DN Cert, Jackie Bailey PhD BSc (Hons), Caroline Glendinning MPhil BA (Hons) \\ Dip Community Work and Yvonne Burkey BA (Hons) \\ National Primary Care Research and Development Centre, University of Manchester, The Williamson Building, \\ Oxford Road, Manchester,UK
}

\author{
Correspondence \\ Sue Kirk \\ National Primary Care \\ Research and Development \\ Centre \\ University of Manchester \\ The Williamson Building \\ Oxford Road \\ Manchester M13 9PL \\ UK
}

\begin{abstract}
Recent health service policy in the United Kingdom has emphasized the need to involve local people in health service planning. This paper will describe how local communities were involved in the development of Primary Care Resource Centres. These centres are designed to provide a base for the delivery of a range of health, social welfare and information services within a community setting. Four centres in the process of being developed in one region were selected for in-depth study. The main method of data collection consisted of semi-structured interviews with key 'stakeholders', namely purchasers and providers of primary health care, social care providers, hospital outreach staff and local community and voluntary group workers (Weiss 1983). This paper examines how the health service organizations developing the centres involved local communities in planning them and the obstacles and difficulties encountered. The paper suggests lessons that can be learned for future community involvement in the planning of local health services.
\end{abstract}

Keywords: community involvement, health service planning, primary care, resource centres

\section{Accepted for publication 17 January 1997}

\section{Introduction}

Since the early 1980s there has been a national policy drive towards consumerism and a market orientation in public sector policies (Clarke et al. 1994). This is evident in the policies for health and welfare, along with those for other public sectors including education and housing. The introduction of markets and quasimarkets was seen as one way of empowering consumers in the public sector, by increasing the range of service options from which they could choose.

Other areas in the public sector have a longer history of active involvement of local people than in health. For example, in the housing sector, tenants' associations have enabled residents to become actively involved in housing management. Similarly, in the education sector the introduction of local management of schools has involved the establishment of governing bodies made up of parents, teachers and local business community representatives.
The funding of regeneration programs also has placed a great emphasis on active community involvement. Some recent primary care developments (e.g. West End Health Resource Centre in Newcastle-uponTyne, Dowsell et al. 1994) have been partly funded through City Challenge and more recently through the Single Regeneration Budget (SRB). The latter emphasizes that community participation should be built into the schemes both as a concept and a process with adequate resources allocated to ensure this occurs (Community Development Foundation 1996).

Involving the community in public sector developments has been argued to have the following benefits (Department of the Environment 1995, Clapham 1996):

- obtaining local peoples' views leads to a better identification of problems in the particular locality

- the community's time, effort and skills increase the total resources devoted to the initiative 
- local knowledge can be useful in helping to target resources where they will be most effective, increasing value for money

- it gives people the self-confidence, skills and knowledge needed to take advantage of opportunities

- publicly funded services should be answerable to their actual and potential consumers.

Gyford (1991) acknowledges there has been little evaluation of the effectiveness of many of the initiatives aimed at involving communities. He also argues:

...introducing elements of user participation both into education and into housing is facilitated by the existence of a clear focal point around which to build structures and procedures, namely the school and the housing estate (p. 69).

Gyford believes this is not the case for the diverse activities of health and social services. However, the development of new primary care facilities may provide just such a focal point for local participation in health service planning and the focus of this paper is on such a development, Primary Care Resource Centres. A study of some of these centres will illustrate the potential of, and obstacles to, community involvement in primary care developments. Before the study is discussed in detail, the background to local involvement in the health service will be described.

\section{Public participation in health service planning}

Consultation and the involvement of local people has been a consistent imperative of health service planning since the early 1990s, and was given particular emphasis with the publication of the discussion paper 'Local Voices' (NHSME 1992). Traditionally, public involvement in the health service has been reactive, in response to negative events such as hospital closures (Heginbotham 1993). Local Voices made it clear that radical changes were required if local people were to have a voice in the shaping of health services. It is a significant document as it emphasizes the importance of public participation in purchasing as distinct from provision (Cooper et al. 1995).

The broad aim of Local Voices was for health authorities to actively and systematically seek the views of local people, taking account, and responding to, their concerns (Rathwell 1992). Local people were to have an ongoing role in all stages of the purchasing cycle rather than one-off consultation exercises (NHSME 1992), so that their views were reflected in establishing priorities, developing service specifications and monitoring and evaluating services. Health authorities were expected to demonstrate how the public had made a 'tangible influence on purchasing decisions' (Donaldson 1995).

Research reveals that although commitment to involving the public is expressed in health authority policy documents, few explain how this might be achieved in practice, or identify how public consultation has influenced purchasing decisions or changed policy (Pickard et al. 1995, Redmayne 1995). It has been suggested that health authorities' apparent reluctance to give the public opportunities to participate in commissioning reflects fears over a loss of control and power (Pickard et al. 1995). Local Voices initiatives themselves have also been criticized on grounds of tokenism and poor methodology (Bowling et al. 1993, Pfeffer \& Pollock 1993, Cooper et al. 1995, Donaldson 1995) and that the document itself lacked guidance on how health authorities were to resolve conflicts of viewpoints (Cooper et al. 1995).

One potential mechanism for involving local people in health service planning is through locality based approaches to commissioning, which many health authorities have now adopted. Locality commissioning has been described as a method by which health authorities organize their commissioning work through decentralization and thus 'get closer' to the population they serve (Øvretveit 1995). Many health authorities are now using locality commissioning as a mechanism for public involvement in purchasing health care according to locally identified needs. However, there is no uniform model of locality commissioning. Some approaches emphasize the involvement of general practitioners (GPs), some the development of community participation, while others aim to involve both groups (Balogh \& Thommasson 1995, Ham 1992, Øvretveit 1995). The localities themselves can be defined in different ways, for example, 'natural' communities, electoral wards, or groupings of GP practices (Ham 1992, Bullen et al. 1996). In theory, a locality approach allows commissioning to be sensitive to local needs while maintaining the power of a large purchasing organization. It also potentially facilitates integrated purchasing with other agencies such as social services.

It is unclear how local communities will be involved in health service planning under a primary care-led system (NHSE 1994). General practitioners are said to operate a demand-led, individual patient-based approach to health commissioning, unlike the health authorities' needs-led population based approach (Øvretveit 1995). It has also been suggested that, along with a focus on the needs of the individual patient, the bio-medical approach and small business orientation of general practice inhibit the broader concept of 
community participation (Brown 1994). Thus while the practice list can provide a basis for involving service users, it may not be an appropriate basis for involving the wider community, unless the practice list and local community are coterminous. Therefore, it is likely that community participation will need to form part of the health authorities' strategic role.

Recent NHS policy continues to emphasize giving a greater voice to users and carers in the development of national and local NHS policy (NHSE 1996). A new NHS initiative 'Patient Participation' attempts to develop this priority into a more explicit strategy (May 1996). Health authorities are encouraged to have strategic plans for ongoing communication and consultation with local people about future service development. They are also expected to be able to demonstrate the impact of consultation on their plans, and how this has been fed back to the local community.

These new initiatives and the philosophy of local involvement described above form the background to the development of Primary Care Resource Centres (PCRCs).

\section{The development of Primary Care Resource Centres}

PCRCs are new or refurbished buildings which house a range of different primary and community health services, social welfare services, health promotion activities and information and advice services. Some also provide a location for consultant outpatient clinics or specialized treatments. They are a resource for both local people and health professionals, serving more than just the people in the immediate locality, unlike traditional health centres.

Some centres have strong roots in broader community development initiatives, where improving access to health services is part of a wider strategy for improving the quality of life locally. Local people are likely to be involved in planning and developing these centres, e.g. West End Health Resource Centre (Dowsell et al. 1994). Other centres have been planned by health authorities or provider trusts, which seek to relocate or 'reprovide' former hospital and community health services, e.g. Lambeth Community Care Centre (Higgs 1985).

From the early 1990s, the former North West Regional Health Authority (NWRHA) undertook a major capital investment programme to develop PCRCs. This initiative was in part a response to the problems of inner-city primary care. It was also seen as a necessary first step in any move of services from secondary to primary health care.

NWRHA provided capital funding for 17 centres from 1994 to 1997, which represented a total invest- ment of $£ 19$ million. This funding had to be allocated before April 1996 when the Authority would be abolished, therefore a tight timescale was imposed on the developments. Other PCRCs in the region have been funded by other sources, including the Private Finance Initiative and Single Regeneration Budget.

The objectives of the PCRC initiative were:

- to extend the range of primary and community health services

- to improve the quality of the physical environment for primary health service provision

- to act as a lever for facilitating a shift in resources from the secondary to the primary health care sector

- to provide a focus for broader action on the health needs of the local community involving local authority services and local people

- to provide a resource not only for professionals and patients, but also for local residents and community groups.

Emphasis was placed on the development of relationships with the local community served by PCRCs, and the centres were seen as focal points to start meeting and consulting the local population. They potentially offered a unique opportunity to involve local communities.

\section{The Evaluation of PCRCs}

A study was undertaken to evaluate the NWRHA's PCRC initiative (Glendinning et al. 1996). As many of the centres were still being planned, the focus of the evaluation was on the processes of planning and developing them. The study focused on the implementation of the PCRC initiative in four sites (Table 1). Three of the centres chosen were funded through the NWRHA initiative, the fourth was chosen for comparison as it was funded through the Private Finance Initiative. Lead 'developers' of the centres were community trusts or health authorities. The main method of data collection consisted of semi-structured interviews with a range of key 'stakeholders' (Weiss 1983) within NWRHA and the four case study PCRCs. These 'stakeholders' included purchasers and providers of primary health care services, social care providers, hospital outreach staff and local community and voluntary group workers. The interview transcripts, together with observational notes were subjected to thematic content and cross-case analyses. Detailed drafts were written up and sent back to participants for comment. This allowed their accuracy to be examined and brought up to date. Moreover, it allowed the validity of the researcher's interpretation to be checked. 


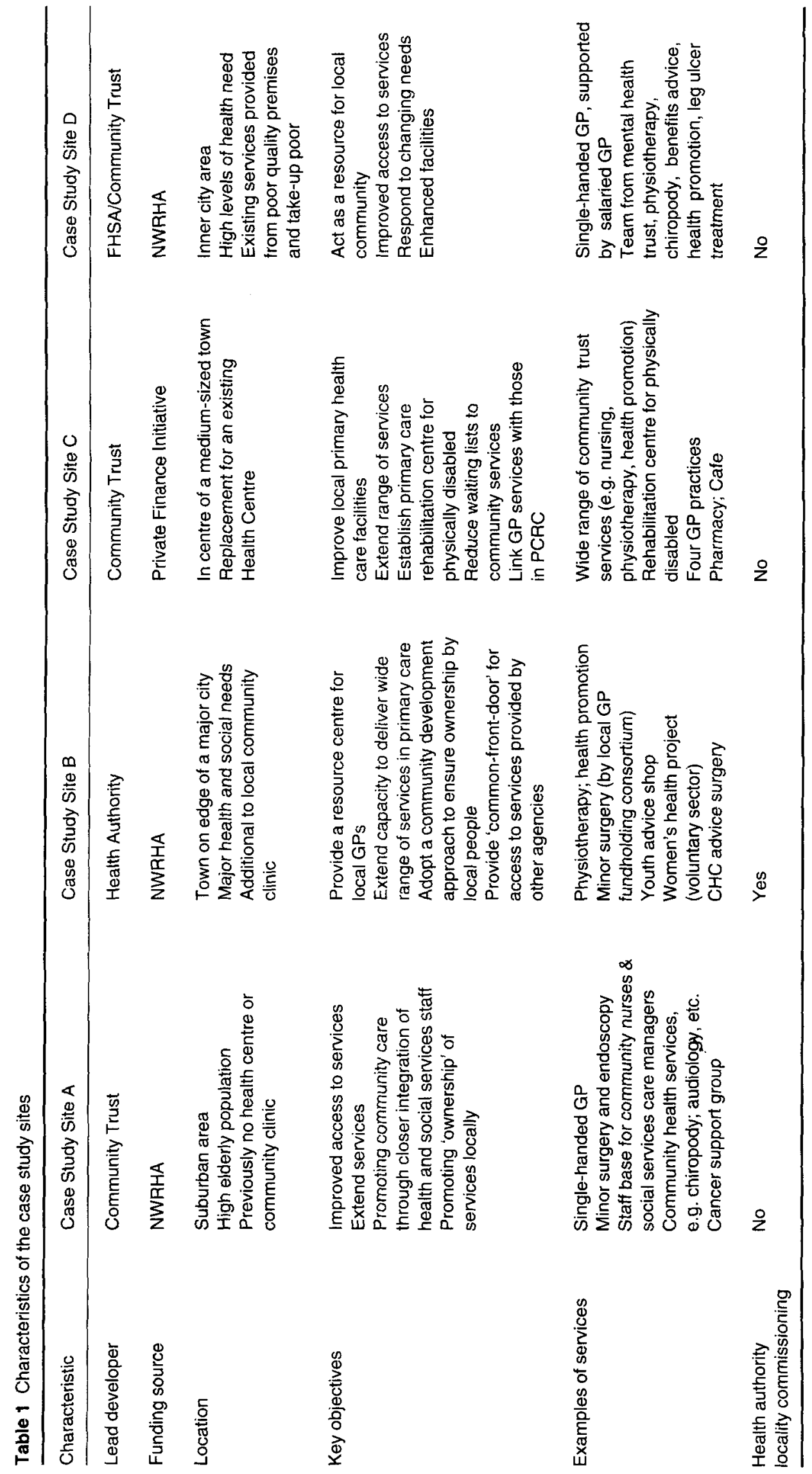




\section{Research findings: community involvement in PCRCs}

\section{Desire to involve local people}

Three of the four centres had explicit objectives which included a community focus (Table 1). However, these objectives were broad and the centre developers generally had no specific plans for how to implement them, apart from centre B, where the health authority had a well-developed locality-based approach to commissioning services. A fundamental element of this was the development of locality centres, which aim to provide services to meet local needs in consultation with both local people and service providers.

Only centre $\mathrm{C}$ had no objective of community participation. Involving the local community in this town centre PCRC was problematic as the population who would use it is widely dispersed. However, some of the services to be based in centre $C$ were targeted at people with physical disabilities, with their own voluntary sector and self-help organizations. Thus, there was a 'community' of potential users who could perhaps have been more actively involved.

\section{Stages in the process of planning and developing centres}

There were three possible stages in the process of planning and developing the PCRCs, each of which could involve local people at different levels. At the first stage, when people were made aware of the funds available for PCRCs, there was an opportunity to involve them in decisions about whether a PCRC was desirable, about possible sites for the location of the centres and the types of services to be run from the centres. At the second stage, after decisions had been reached about a centre's location, local people could be involved in more detailed planning about the services that might be based in the centres and in decisions on the design of buildings. At the final stage, once the centres were opened, there were potential opportunities for ongoing involvement in service monitoring and planning; as members of local community groups based in or using the centres; and in the management of the centres.

\section{Constraints}

There were various constraints to the planning and development of the centres as perceived by those people involved in their development. The tight timescale imposed on the development of the centres by NWRHA constrained the levels and type of community involvement that could be undertaken. For example, in centre A, the Community Health Council was commissioned to set up and run a public consultation exercise within 6 weeks. Secondly, some of the local centre developers understood that NWRHA required certain services to be available in the centres, for example, a general practice 'presence', minor injuries' services and extended opening hours. Therefore there were already certain 'givens' which the community would have no option but to accept. Further constraints were the limitations on the availability of land or existing buildings that could be refurbished, again within the tight time scale. These constraints undermined attempts at local participation as it was clear some important decisions had already been taken. However, these constraints did not necessarily apply once the centres were open.

\section{Community involvement at the initial and detailed planning stages}

\section{Initiators of community involvement in centres}

In centre $A$, the community trust which developed the centre commissioned the local Community Health Council $(\mathrm{CHC})$ to run a public consultation exercise (Table 2). With centre $\mathrm{C}$, neither the health authority nor the Community Health Council had conducted any consultation exercises about the development of the PCRC, leaving the consultation process in the hands of the trust. However, stakeholders at the trust appeared to consider that public consultation was part of the purchaser's role. In the case of centre B, the local authority had a joint role with the health authority in consulting local people, through a health needs assessment exercise.

\section{Methods of involving the community}

The methods chosen to involve the community included public meetings, use of the media, and health needs assessment exercises. The health needs assessment exercise of centre B, adopted a community development approach, with local people being fully involved in both identifying the issues to explore in interviews, and in collecting the data. It was hoped that the project would be a springboard for ongoing community involvement and participation, and for joint working between the different agencies involved.

For centre A, the CHC targeted groups in the area seen as having high health needs, for example, elderly residents and young people. One way the $\mathrm{CHC}$ targeted the elderly population was through a coffee morning. Invitations were handed out by Social Services staff to their clients. Local hairdressers and organizations that worked with elderly people in the 
Table 2 Community involvement in planning and developing PCRCs

\begin{tabular}{|c|c|c|c|c|}
\hline Site & A & $\mathrm{B}$ & $\mathrm{C}$ & D \\
\hline \multicolumn{5}{|c|}{ Community involvement in the early stage of planning PCRCs } \\
\hline Initiators & $\begin{array}{l}\text { Community Health } \\
\text { Council }\end{array}$ & $\begin{array}{l}\text { Health Authority \& } \\
\text { Local Authority }\end{array}$ & Community Trust & Health authority \\
\hline $\begin{array}{l}\text { Local community } \\
\text { involved }\end{array}$ & $\begin{array}{l}\text { General public; } \\
\text { targeted groups, } \\
\text { e.g. elderly, } \\
\text { young women; } \\
\text { voluntary \& } \\
\text { community groups }\end{array}$ & $\begin{array}{l}\text { Community and } \\
\text { voluntary groups; } \\
\text { local people }\end{array}$ & $\begin{array}{l}\mathrm{CHC} ; \text { voluntary } \\
\text { groups }\end{array}$ & $\begin{array}{l}\text { Community } \\
\text { development } \\
\text { worker; community } \\
\text { and voluntary } \\
\text { groups }\end{array}$ \\
\hline interviews & $\begin{array}{l}\text { Public meetings; } \\
\text { coffee morning; } \\
\text { media campaign; }\end{array}$ & $\begin{array}{l}\text { Health needs } \\
\text { assessment exercise; } \\
\text { health fair; roadshow }\end{array}$ & $\begin{array}{l}\text { Meetings; public } \\
\text { displays }\end{array}$ & $\begin{array}{l}\text { Health needs } \\
\text { assessment } \\
\text { exercise }\end{array}$ \\
\hline \multicolumn{5}{|c|}{ Community involvement in detailed planning before centres opened } \\
\hline Initiators & Community Trust & Health Authority & Community Trust & Community Trust \\
\hline $\begin{array}{l}\text { Local community } \\
\text { involved }\end{array}$ & $\begin{array}{l}\text { Voluntary groups, } \\
\text { community groups }\end{array}$ & $\begin{array}{l}\text { CHC; community } \\
\text { health forum }\end{array}$ & $\begin{array}{l}\mathrm{CHC} \text {; voluntary groups; } \\
\text { health centre users }\end{array}$ & $\begin{array}{l}\mathrm{CHC} \text {; Council for } \\
\text { Voluntary Services, } \\
\text { Citizens Advice } \\
\text { Bureau }\end{array}$ \\
\hline Methods & $\begin{array}{l}\text { Meetings; design plans } \\
\text { displayed in local library }\end{array}$ & Meetings & $\begin{array}{l}\text { Meetings; local media; } \\
\text { displays in locality }\end{array}$ & Meetings \\
\hline
\end{tabular}

area also invited people, and transport was provided. To target the younger population, which was seen as a 'hard to reach' group, the $\mathrm{CHC}$ involved young peoples' voluntary groups and a youth worker. Attempts were made to consult through the schools and interviews were undertaken with young women.

\section{Difficulties experienced in consultation}

Some respondents raised difficulties that were involved in deciding whom to consult within a locality and who represented the 'community'. Different parts of the community involved in the consultation exercises had competing interests. For example, with centre A, elderly residents feared involving local young people due to past problems with vandalism of the local community centre and schools. A stakeholder from centre $D$ further highlighted this problem:

I think representative groups or identifiable groups were consulted, whether that actually constitutes the local community, is perhaps ... a moot point. I know from bitter experience that a lot of these people are self selected and almost by definition because of the kinds of people they are, they tend to represent their own sphere of interest rather than necessarily the whole community. ... short of an invitation to every household I don't see how you can literally consult the whole community (centre D stakeholder).

Other difficulties with involving the local community experienced by centre developers were the absence of a clear vision of what a PCRC was, or a range of options available from which people could choose:

Another problem is consulting on what you don't know is coming in. Not only consulting on what services there might be but also we were consulting blindly because we didn't have a range of ... these are the things you can have, to create pictures in people's minds, for them to think that there were possibilities. No comparisons available about what centres can look like ( $\mathrm{CHC}$, centre A).

Closely linked to this last issue is the fact that there were difficulties in consulting people about a new development, because people were more familiar with consultation over events such as hospital closures. The $\mathrm{CHC}$ representative who ran the early public consultation exercise for centre $\mathrm{A}$, found the response to some of the CHC's consultation initiatives disappointing, and compared it to the response they received if consulting about closing a hospital:

After being involved for years and years saying let's shut somewhere down, if you say let's open somewhere it does 
not seem to generate the same level of interest. We pushed and struggled to get people's view forward.

Respondents were critical of the level of involvement of local people in the decisions that were taken about the PCRCs. With centre D, there was a widespread feeling that no-one really had much choice in the decision to go ahead with a PCRC in the district or its precise location, therefore consultation at the early stages would have been disingenuous. The $\mathrm{CHC}$ for centre $D$ was quite critical of the aims of the consultation process and the level of involvement that people had had in the decisions that were taken:

I make the distinction between consultation and involvement ... consultation comes after decisions have already been made and then you tinker about with them ... and in some ways it would have been a false consultation if they'd gone out to local people and said 'What do you want?' Because I can't see that many people would have come back and said what they wanted was another glorified health centre. In that sense the timescale and the directions the RHA had given precluded that ... the decisions had already been made.

\section{Impact of community involvement}

Due to the constraints reported earlier, community involvement with the early stages of development of the centres was fairly limited. With centre A, the consultation supported the need for the development of a health facility in the area, which the community had been campaigning for over many years. Services which people identified as being needed in the area were consistent with the services the trust developing the centre wanted to bring into the locality, and were included in the service specification for the centre. In the consultation events, there was dispute and debate about the location of the site. One argument that came forward from local people was not to have a new building, but to refurbish an old property in the area. However, the lack of available sites and the tight timescale precluded the developers from acting on this and a new building was chosen.

For centre $B$, respondents to the health needs assessment exercise wanted, firstly, to establish a resource centre, with the local community being involved in its development and operation; and, secondly, wanted to re-establish a community health forum in which issues of concern about health could be raised. When the PCRC went ahead, it was seen as demonstrating to the community that action had been taken following the health needs assessment project:

It's the implementation of what the people asked for ... a perfect opportunity for the community to have a voice, they've never been given that in the past and I think if you didn't listen to them this time then you would lose all credibility (Community/voluntary group).

However, although centre $B$ appeared to be a response to the health needs assessment exercise, there was some dissatisfaction with subsequent opportunities for local involvement especially over the services that would be provided from the PCRC and on the community's future role with the centre:

The community could have been more involved in the planning of it, the actual planning of the centre ... who should be in it ... I don't know why that hasn't happened (Community/voluntary group).

This dissatisfaction with the lack of involvement in the detailed planning stages of the development of the centres was echoed by respondents at the other centres.

\section{Plans for the ongoing involvement of local communities in PCRCs}

Service planning and development

The developers of two PCRCs planned to involve the local community in future developments and could identify possible mechanisms such as community health forums for this. Local people at these centres, however, were not optimistic about the level of involvement they would have in decision making. They feared that this would amount to informationgiving, as had occurred in the planning of the centres, rather than any true participation:

The Community Trust have never involved anyone in the planning apart from seeing the plans on the wall. The trust don't reach out (to the community), there won't be much ownership (CHC centre A).

At centre B some respondents felt that the health needs assessment project had raised local people's expectations of involvement and were concerned that it was seen by the health authority as an end point:

The health needs assessment isn't a one-off, the involvement isn't a one-off, its an ongoing process and an ongoing dialogue. We're missing the opportunity of the good relationships that have been built up (local authority centre B).

However, following the opening of centre $B$, the health authority and local authority appointed a community health development worker who would focus on developing and facilitating the local community's involvement in the PCRC and in promoting links between services and the community.

At the other two centres there were no plans to involve local people on an ongoing basis. One of the developers, a community trust, considered this to be the role of the health authority through its locality 
commissioning approach. The trust's only commitment to obtaining the views of users was as part of the service evaluation process.

\section{Use by local community groups}

Community representatives considered that it was important for community and voluntary sector groups to use PCRCs as a way of both promoting local people's sense of ownership of the centre and giving centres a less formal image:

....a little bit more voluntary [sector] input would take away that officialdom, that formal atmosphere (community/ voluntary group centre B).

A small number of community groups would be using centres $A, B$ and $C$ for meetings and a voluntary sector service was one of the core services at centre $B$. Although a number of local groups had expressed an interest in using centre $D$, the trust had not entered into any agreements for such use. Charging policies for room usage differed between the sites and may relate to the emphasis placed on community involvement. While some of the developing organizations intended to facilitate community involvement in the PCRCs through providing free access to rooms, the trust developing centre $C$ planned to charge such groups for use. Clearly community trusts face revenue constraints that may act as a disincentive to allowing centres to be used by community groups unless they receive support from health authorities. This is illustrated by centre $\mathrm{B}$, which was developed by a health authority committed to promoting the use of the facilities by local community and voluntary groups and who were not charging groups using the centre on a sessional basis. Some respondents were concerned that the provision of free or subsidized accommodation would only apply to health-related groups, and this might be inappropriate in areas with multiple social problems. Narrow definitions of health may limit the potential of centres to be a focus for improving the health of local communities and for inter-agency working.

Originally, there were plans for most of the centres to provide a base for minor injury centres and GP 'outof-hours' services, which would have led to the buildings being open in the evenings and at weekends. However, such plans were not realised, which may affect the potential use of the centre by community groups who wish to meet at these times.

\section{Role in the management of the primary care resource centres}

There were no plans for involving any community representatives in the management of any of the four study centres, although it was possible that the community health development worker in centre B might be a member of a future management committee. Rather it appeared that a local GP fundholding consortium and the health authority would play the key role in the centre's strategic management and development. Some stakeholders at centres B and D, felt however, that it would be important for management committees to have local community representation on them, to ensure the perspectives of local people were incorporated into the development and management of the centres. Representation on a management committee was also seen as one way of facilitating the development of a sense of ownership by the community.

\section{Discussion}

Primary Care Resource Centres are a new type of development which provide a great opportunity to give local people a voice in service planning and delivery. The research reported here has focused on the approaches taken by the health service organizations developing four PCRCs to involve the community. Although involvement of the local community was a recognized principle for three of the four centres, there were no clear models developed or evaluated to implement this objective. Nor, except for centre B, was there evidence of clear longer-term strategies for community involvement. The research identified a number of stages at which the local community could be involved in the PCRCs: in the early stages when decisions about the location of the centre and possible services were made; in the more detailed planning of the service configuration; and following opening when local people could have a role in the ongoing service planning, monitoring and management of the centres.

Several points highlighted by the research have implications for involving local people in primary care developments. First, there was the difficulty of consulting about new developments as people tend to be more familiar with reacting to health service plans (particularly hospital closures), rather than with putting forward new ideas and proposals. Secondly, the 'community' is not a homogeneous entity but consists of different groups and individuals who may have competing interests. Engaging with these different groups, particularly so-called 'hard to reach' groups such as young people and people from ethnic minorities, and attempting to meet competing needs will present particular challenges. Organizations who are attempting to involve communities need to recognize, and take into account, the different constructions of its meaning which those within and outside the 
community hold (Jewkes \& Murcott 1996). Creative and different methods may be needed to involve different sections of the community, as well as time and dedicated resources to develop the mechanisms for involvement. There may be a need for NHS planners and managers to work with broader definitions of 'health' and 'health gain', which are not constrained by the narrow remit of health service activities, otherwise attempts to involve local people in new, communitybased health services will fail to address the issues which are important to people's lives and to the wider determinants of health.

Various issues which need to be addressed when involving local people in health service planning emerged. There are different levels of community involvement and participation, from informationgiving through to active decision-making (Wilcox 1995). Activities were often described by PCRC developers as 'consultation'. However, particularly in the later stages of the developments, what occurred was the developers giving the community information about their plans for the centres rather than local people having a more active role in decision-making. Developers need to be clear about why community involvement is needed and what level of involvement is desired, from the community's perspective as well as other organizations. Confusion over the scope of community involvement, and the lack of shared definitions of terms such as 'consultation', can result in dashed expectations, and increase the risk of any barriers being reinforced. Therefore, it is important for developers to be clear and open about in which decisions the public can genuinely participate, and which decisions have already been taken elsewhere. Furthermore, it should be recognized that consultation and community involvement are not one-off events, but are ongoing and iterative processes. Feedback needs to be given on how consultation or involvement has influenced plans for service development.

At a fundamental level, the philosophy of the developing organization, in terms of public participation, will be a key factor in the extent to which local people are involved in primary care developments. It has been suggested that a cultural shift is required if health service professionals and organizations are to be truly committed to public participation in health service planning, and move from a consumer to an empowerment agenda (Layzell 1994, Lupton et al. 1995). While at a national policy level there is apparent support for public participation, at a local level this appears often to be interpreted in its narrowest sense. As Lupton et al. (1995) have noted:

...the window of opportunity for public involvement in the NHS appears to be barely open ...... the vogue for public involvement is largely driven by a managerialist rather than a democratic agenda.
Particular skills are required to build bridges between the variety of individuals and groups that make up a community and health service organizations. This begs the question of whose role it should be to engage with the public and who has the appropriate skills. Both health authorities and community trusts may have expertise in working with local people. Health authorities may have expertise obtained through conducting 'Local Voices' and health needs assessment exercises. Whereas that of community trusts may largely have been acquired through the work of the professionals they employ. However, health service organizations may have more skills in involving specific user groups rather than local communities (Donaldson 1995). Collaborating with other organizations such as community health councils, councils of voluntary service and local authorities may help in the process. The potential role of community development workers in facilitating local community involvement in service planning also needs to be explored.

Research into the most effective techniques for involving the community in new health developments is required. There have been no attempts to evaluate the best methods of involving the public, or to evaluate the changes made to purchasing as a result of their participation (Donaldson 1995). Lessons can be learned both from other PCRCs which have more community involvement (for example, the West End Health Resource Centre in Newcastle and the Vauxhall Centre in Liverpool), and from other public sectors such as housing and education. The impact of community involvement on the 'success' of new primary care developments such as PCRCs should be evaluated.

Public involvement in health service planning presents many challenges to health service organizations, in terms of cultural change, and how to engage with local people in practice. It would appear to be most appropriate for purchasers, as the organizations with responsibility for strategic planning, to take on this role. It is important that community involvement is an integral part of the work of health authorities, rather than a 'bolt-on extra' (Layzell 1994), and models of locality commissioning may offer one means of achieving this. There will be many 'voices' to listen to, and potentially many conflicting views on the future shape of local health services. PCRCs could provide both the starting point and the focus for exploring how the public can be involved in the planning of local health services.

\section{Acknowledgements}

This study was funded by the former North West Regional Health Authority. Jackie Bailey was supported 
by a Medical Research Council Health Service Research Training Fellowship. The views expressed in this paper are those of the authors and do not reflect those of the funding body. The authors would like to thank all the participants in the study and colleagues who commented on earlier drafts of the paper in particular, Tom Butler.

\section{References}

Balogh, R. \& Thommasson G. (1995) The Persuaders. Health Service Journal 105 (5465), p. 26.

Bowling, A., Jacobson, B. \& Southgate L. (1993) Health service priorities: explorations in consultation of the public and health professionals on priority setting in an inner London Health District. Social Science and Medicine 37 (7), 851-7.

Brown I. (1994) Community participation for general practitioners: perceptions of general practitioners and community nurses. Social Science and Medicine 39 (3), 335-344.

Bullen, N., Moon G. \& Jones K. (1996) Defining localities for health planning. Social Science and Medicine 42 (6), 801-16.

Clapham D. (1996) Resident's attitudes and perceptions. Position paper. Joseph Rowntree Foundation Area Regeneration Programme, York.

Clarke J., Cochrane A. \& McLaughlin E. (Eds) (1994) Managing Social Policy. SAGE, London.

Community Development Foundation. (1996) Regeneration and the Community: Guidelines to the Community Involvement Aspect of the SRB Challenge Fund. Community Development Foundation, London.

Cooper, L., Coote, A \& Davies A. (1995) Voices Off: Tackling the Democratic Deficit in Health. Institute for Public Policy Research, London.

Department of the Environment. (1995) Involving Communities in Urban and Rural Regeneration: A Guide for Practitioners. Department of the Environment, London.

Donaldson L. (1995) The listening blank. Health Service Joumal 105 (5471), 22-24.

Dowsell T., Drinkwater C. \& Morley V. (1994) Developing an inner city health resource centre. In $Z$. Heritage (Ed.) Community Participation in Primary Care. The Royal College of General Practitioners, Occasional Paper 64.

Glendinning C., Bailey J., Burkey Y., Gosden T. \& Kirk S. (1996) An Evaluation of Primary Care Resource Centres in the
North West of England. National Primary Care Research and Development Centre Report, University of Manchester, Manchester.

Gyford J. (1991) Citizens, Consumers and Councils. Macmillan Education Ltd, Basingstoke.

Ham C. (1992) Local heroes. Health Service Journal 102 (5329), 20-21.

Heginbotham C. (1993) Listening to Local Voices, NAHAT Research paper 9. NAHAT, Birmingham.

Higgs R. (1985) Example of intermediate care: the new Lambeth Community Care Centre. British Medical Journal 291, 1395-1397.

Jewkes R. \& Murmott A. (1996) Meanings of community Social Science and Medicine 43 (4), 555-563.

Layzell A. (1994) Perspectives on purchasing: local and vocal. Health Service Journal 104 (5386), 28-30.

Lupton, C. Buckland, S. \& Moon G. (1995) Consumer involvement in health care purchasing: the role and influence of the community health councils. Health and Social Care in the Community 3 (4), 215-226.

May L. (1996) The choice is yours. NHS Magazine 5, 15-17.

NHSME (1992) Local Voices: the Views of Local People in Purchasing for Health. HMSO, London.

NHSME (1994) Developing NHS purchasing and GP fundholding: towards a primary care-led NHS. EL (94)79. Department of Health, London, .

NHSE (1996) Priorities and Planning Guidance for the NHS: 1997/98. Department of Health, London.

Øvretveit J. (1995) Purchasing for Health. Open University Press, Buckingham.

Pfeffer N. \& Pollock A. (1993) Public opinion and the NHS: the unaccountable in pursuit of the uninformed. British Medical Journal 307, 750-1.

Pickard, S., Williams, G. \& Flynn R. (1995) Local voices in an internal market: the case of community health services. Social Policy and Administration 29 (2), 135-149.

Rathwell T. (1992) A voice in the wilderness. Health Service Journal 102 (5326), 21.

Redmayne S. (1995) Reshaping the NHS: strategies, priorities and resource allocation NAHAT Research paper 16 . NAHAT, Birmingham.

Weiss C.A. (1983) The stakeholder approach to evaluation: origins and promise. In A.S. Bryk (Ed.) Stakeholder-Based Evaluation. Jossey-Bass, San Francisco.

Wilcox D. (1995) The Guide to Effective Participation. Partnership Books, Brighton. 